\title{
1 Evaluation of DEM size and grid spacing for fluvial patch-scale roughness
}

2 parameterisation.

3 Jane Groom (jgro800@aucklanduni.ac.nz),

4 Stephane Bertin (s.bertin@ymail.com) and

$5 \quad$ Heide Friedrich (h.friedrich@auckland.ac.nz)

6 Department of Civil and Environmental Engineering, University of Auckland, Auckland, New 7 Zealand.

8

\section{Highlights}

- Facilitates the improvement of understanding the analysis of topographic data

11 - A single roughness parameter is inadequate for describing patch-scale roughness

12 - A DEM size exceeding $16 \times \mathrm{D}_{50 \mathrm{~A}}$ is appropriate to characterise grain-roughness

- Grid spacing should reflect the scale of research

- This analysis can be used on a variety of applications using topographic data

\section{Abstract}

17 Surface roughness is a term used in fluvial research without an unanimousdefinition, and 18 clarification of the term and improved parameterisation is needed in future research. Improvements to the collection of topographic data, using photogrammetry, have provided accurate digital elevation models (DEMs) of field and laboratory gravel-bed patches. In this

21 study, we use a moving-window process for analysing spatial variability within DEMs. Using 22 this information, and in unison, we consider the effect of DEM size and grid spacing on an 23 extensive range of roughness parameters, in order to provide insights for obtaining grain- 
24 roughness statistics. We show that DEM size influences the calculated roughness statistics, 25 and the observation of plateaus in statistics for DEM window sizes above $16 \times \mathrm{D}_{50 \mathrm{~A}}$ in both 26 directions (where $\mathrm{D}_{50 \mathrm{~A}}$ is the median grain size of the bed-surface material) suggests this as a 27 minimum DEM size for grain-scale roughness analysis. We further find that the DEM grid 28 spacing should be $1 \mathrm{~mm}$ or below, in order to adequately capture grain roughness, as coarser 29 resolutions failed to detect particle imbrication. Finally, variability in roughness parameters 30 was evident due to the natural spatial variation in gravel-bed microtopography, suggesting using a single roughness parameter is not appropriate to holistically describe the roughness of 32 a gravel patch.

\section{Key Words}

34 Grain-roughness; DEM; parameterisation; close-range photogrammetry

\section{Introduction}

36 Calls to re-evaluate the term for roughness and improve parameterisation in future research 37 have been made (Lane, 2005; Rice et al., 2014; Martinez-Agirre et al., 2016), due to the term 38 being used frequently, albeit with little definition (Morvan et al., 2008; Jia and Hu, 2015).

39 Surface roughness in fluvial environments such as gravel-bed rivers influences the dynamic interactions between flow, sediment transport and ecology (Aberle and Nikora, 2006; Hodge et al., 2009a; Baewert et al., 2014; Curran and Waters, 2014). Previous parameterisation of

42 roughness included subjective estimations of coefficients or the use of roughness heights based on grain size and velocity profiles (Wilcock, 1996, Smart et al., 2004). However there has been a recent move to obtaining quantitative roughness parameters including bed45 elevation moments such as standard deviation, skewness and kurtosis determined from transects or digital elevation models (DEMs) (Aberle and Nikora, 2006). 
47 Research on gravel-bed rivers now gathers information collected from 'patch-scale' DEMs for roughness parameterisation, although studies differ in data collection (e.g., the size and resolution of measurements) and analysis methods (e.g., detrending method and roughness parameters used). Therefore, explicit definitions of a gravel patch and patch-scale DEMs are

51 still lacking; yet, it is understood the size and resolution of measurements should allow for 52 adequate representation of the surface character (Hodge et al., 2009a). Roughness parameters are used as inputs for both hydraulic and morphodynamic models, such as for determining flow resistance (Aberle and Smart, 2003; Tuijnder and Ribberink, 2012). Measurements of bed topography (e.g., the standard deviation of bed elevations) are also helpful for obtaining estimates of sediment size on the bed surface (see Pearson et al., 2017 for a review).

57 Therefore, accurate parameterisation of roughness is required to avoid error propagation in several applications of fluvial science and modelling (Smart et al., 2002; Lane, 2005; Morvan et al., 2008). One step towards achieving accurate roughness parameterisation is to provide guidance to researchers on how to work with topographic datasets.

61 This analytical paper aims to provide insights into patch-scale gravel-bed DEM analysis for obtaining roughness information. A combination of laboratory and field data is used, with the application of an analytical process for fluvial gravel-bed DEMs and the consideration of an extensive range of roughness parameters. Firstly, this study considers roughness spatial variability.Previous research considered the small-scale spatial variability in grain size (Crowder and Diplas, 1997), with applications to evaluate the effect of sampling area on the accuracy of image-based grain size measurements (Graham et al. 2010), and to explain spatial differences in grain entrainment (Piedra et al. 2012). We recently presented new results on the spatial variability and scaling of surface structure (i.e., topography) in gravelbed rivers, allowing the isolation of roughness scales from DEMs (Bertin et al., 2017). This paper continues on this emerging avenue of research, with a wider selection of roughness 
72 parameters assessed. Secondly, this paper assesses the combined effect of DEM size and grid 73 spacing on output roughness parameters. The current scope of literature in relation to each of

74 these objectives is discussed in more detail in the background section following.

\section{Background}

76 An overview of the procedure for analytical processes considered throughout this study is 77 provided in Figure 1. This visually presents the different analytical steps investigated, 78 including the effect of DEM size (i.e., the spatial extent of the DEM or measured patch, Step 79 1) and grid spacing (equivalent to DEM resolution, Step 3). Step 1 is specific to the technique 80 of digital photogrammetry in the generation of point clouds, but the subsequent steps are applicable to all researchers, from a broad range of disciplines, analysing topographic

82 datasets. Complete details of the processes will be outlined in the methodology section.

\section{DEM size}

84 Roughness values are dependent on a suitable DEM size, as this determines the scale over 85 which the roughness is calculated (Florinsky and Kuryakova, 2000; Smith, 2014). Research on grain roughness suggests that the size of the gravel patch measured needs to be large enough to capture a range of sediment sizes, including several large grains (Hodge et al., 2009a). However, a more quantitative guideline for the size of a DEM is required (Step 1,

Figure 1), as patch-scale research has used DEM sizes ranging from $0.1 \mathrm{~m}^{2}$ to $1 \mathrm{~m}^{2}$ (Hodge et al., 2009a; Mao et al., 2011; Ockelford and Haynes, 2013; Rice et al., 2014). Recent literature deemed patch sizes, which equate to $21 \times \mathrm{D}_{50}$ in both directions, suitable for analysis of grain roughness changes for flows below entrainment threshold (Ockelford and Haynes, 2013). Unfortunately, reasons behind this decision were not presented and it is not clear if $\mathrm{D}_{50}$ refers to the bulk mixture or bed surface sediment, which is problematic when grain size varies greatly between surface and subsurface, such as for armoured beds. 
Step 1:

Data acquisition

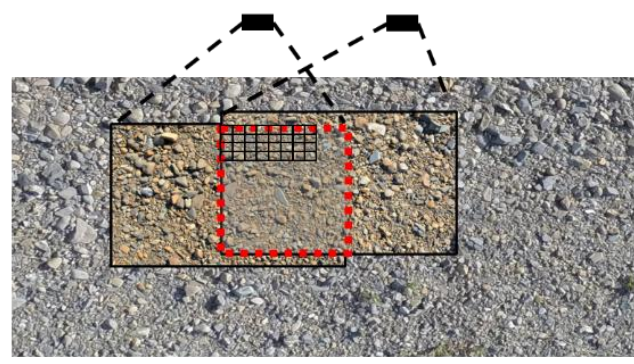

Photogrammetry; where the common field of view (CFoV) (overlap in two images) determines the patch size (red dashed line) for analysis.

Pixel size (small black squares) determined by sensor size, focal length and camera distance.

Step 2: Data processing

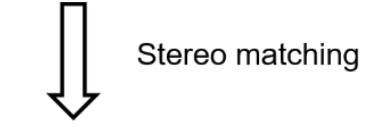

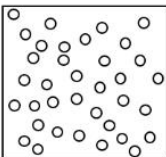

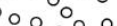

\section{Step 3: Generation of DEM}

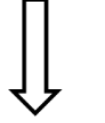

Interpolation onto regular grid

(e.g. determining grid spacing) determined by pixel size and size determined by CFoV.

$8 \pi 000000$ 00000 000000 000000 0 O 00000 000000

DEM maximum size (e.g. patch size) determined by CFoV and grid spacing (thick black lines) is $\geq$ pixel size which can be user defined.

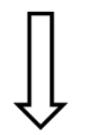

Transect of DEM (red line) schematically depicting grainroughness (blue dashed line).

\section{Step 4: Moving-window} analysis
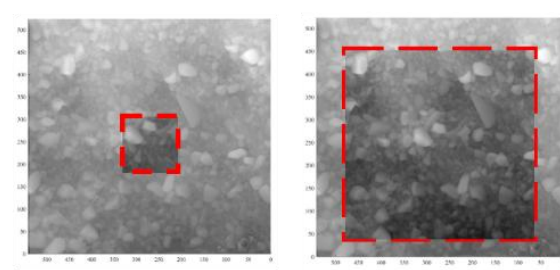

Moving-window size selection based on $D_{50 \mathrm{~A}}$ values.

Example depicts $4 \times \mathrm{D}_{50 \mathrm{~A}}$ (left) or $16 \times D_{50 \mathrm{~A}}$ (right) in both directions.

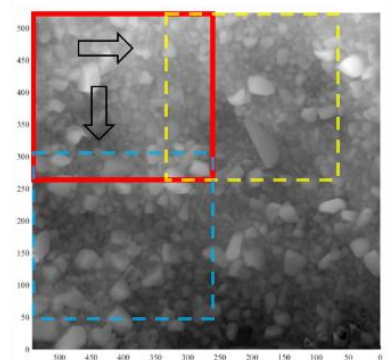

Moving window analysis with user defined window size (e.g. $10 \times \mathrm{D}_{50 \mathrm{~A}}$ in both directions), example of $25 \%$ overlap for clarity purposes.

Black arrows indicate moving window in both directions. New windows defined with coloured dashed lines. 
97 Figure 1. Overview diagram of the generation of topographic data using digital 98 photogrammetry and analytical processes discussed further, including interpolation using 99 varying grid spacingand a moving window technique.

100 A moving-window approach (Step 4, Figure 1) was used to determine the grain-size 101 variability of a river reach (Crowder and Diplas, 1997), and to evaluate DEM error spatial 102 distribution for various survey strategies and interpolation methods (Heritage et al., 2009; 103 Milan et al., 2011). Further, studies in different applications, including large scale floodplain 104 analysis, have altered the DEM size (using a moving window technique with a window radius 105 ranging from $1 \mathrm{~m}$ to $1000 \mathrm{~m}$ ), which allowed for the identification of threshold sizes for

106 DEMs to produce topographic metrics (Florinsky and Kuryakova, 2000; Scown et al., 2015).

107 These papers highlight the importance of establishing the scale of interest and using this 108 choice to select a suitable DEM size.

109 Recent use of moving windows of different sizes on gravel patches distinguished roughness 110 signatures of grains and bedforms (Bertin et al., 2017). Contrasting with grain roughness, 111 measures of bedform roughness did not always reach stable values with window-size 112 increases, suggesting that patch-scale DEMs may be limited in use to the analysis of grain 113 roughness (Bertin et al., 2017, Powell et al., 2016). Just like Graham et al. (2010) using grain114 size spatial variability for examining the effect of sampling area on the accuracy of grain size 115 measurements, previous research suggests that knowledge on roughness spatial variability 116 can provide guidance towards an appropriate DEM size for analysis of surface roughness, 117 which will be evaluated in this study. 
118 In reporting our experiments, we therefore use the term DEM size to refer to two things,

119 which is worthy of clarification: (i) DEM size efers to the size of the gravel patch measured,

120 which is a 'constant' for each patch and is presented in Table I; (ii) DEM size is then altered

121 using moving windows, and we use our measurements of roughness spatial variability for

122 different window sizes to identify a minimum DEM size for roughness analysis.

\section{DEM grid spacing}

124 Future research using high resolution data needs to consider the level of detail required for 125 the application (Smith, 2014). For example, the grid spacing (i.e., DEM resolution) used 126 when converting a point cloud to a DEM (Step 3, Figure 1) also determines the scale over

127 which roughness is calculated, with previous studies stating patch-scale investigations require 128 higher resolution and precision (Smith et al., 2012; Smith, 2014). Studies on various scales 129 from soil properties, gravel surfaces and catchment landscapes, have found that changes in 130 measurement resolution influence the obtained roughness values or topographic parameters 131 and affect DEM accuracy (Zhang and Montgomery, 1994; Smith, 2014; Trevisani and 132 Cavalli, 2016; Grieve et al., 2016; Bertin and Friedrich, 2014; Lane et al., 2000; Gao, 1998; 133 Erskine et al., 2007; Milenković et al., 2015; Barber et al., 2016). Thus the scale of the 134 process investigated should influence grid spacing choice

135 Studies on gravel beds have used grid spacing including $0.1 \mathrm{~mm}, 1 \mathrm{~mm}$ and $5 \mathrm{~mm}$, regardless 136 of sediment size on the patch (Buffin- Bélanger et al., 2006; Ockelford and Haynes, 2013; 137 Hodge et al., 2009a; Bertin and Friedrich, 2014; Curran and Waters, 2014). Due to this range, 138 it is important to investigate the effect of a resolution below, and above, the $1 \mathrm{~mm}$ resolution 139 commonly used for gravel patches, in order to provide an indication to the optimal grid spacing for use in grain roughness analysis. 
141 Methodology

142 Gravel-bed patches and digital elevation models (DEMs)

143 DEMs representing the microtopography of five gravel-bed patches from different 144 geomorphic settings (i.e. collected from both the field and a laboratory flume) were used for 145 the study (Figure 2).

146 Three DEMs collected in August 2014 from the Whakatiwai River, a small gravel-bed stream 147 located in New Zealand North Island, and presented in Bertin and Friedrich (2016), form the 148 field surfaces. Patches from three exposed and vegetation-free gravel bars (labelled "Field 1" 149 to "Field 3", with numbers increasing upstream) were selected for measurements, covering a 150 range of sediment size and surface structure (Table I). Each patch was selected at the bar 151 head close to the water edge, for both consistency in the measurements, and ensuring the 152 surfaces are regularly water-worked under similar hydraulic conditions.

153 Two armoured gravel beds called "Lab 1" and "Lab 2" formed in a non-recirculating tilting 154 flume with glass side-walls ( $19 \mathrm{~m}$ long, $0.45 \mathrm{~m}$ wide and $0.5 \mathrm{~m}$ deep), with a flume slope set 155 at $0.5 \%$, are also examined. The experimental beds were obtained from water-working two 156 distinct sediment mixtures. A constant flow rate of $84 \mathrm{~L} / \mathrm{s}$ (mean flow velocity $=0.82 \mathrm{~m} / \mathrm{s}$, 157 shear velocity $=0.077 \mathrm{~m} / \mathrm{s}$ and uniform water depth $=0.225 \mathrm{~m}$ ) was applied until the rate of 158 sediment transport dropped to less than $1 \%$ of the initial transport rate. Both sediment 159 mixtures were prepared from distinct but slightly bimodal alluvial sediments (15\% sand and $16085 \%$ gravel, and 9\% sand and 91\% gravel, respectively), with size ranging from 0.7 to $35 \mathrm{~mm}$ 161 (Table I). The tests were performed under condition of sediment starvation (i.e., no sediment 162 feeding). 


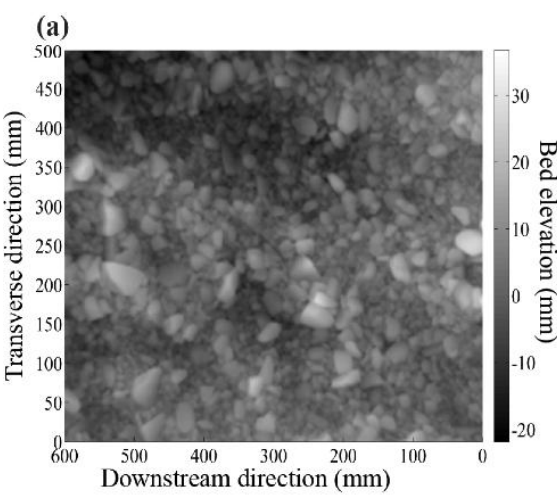

(d)

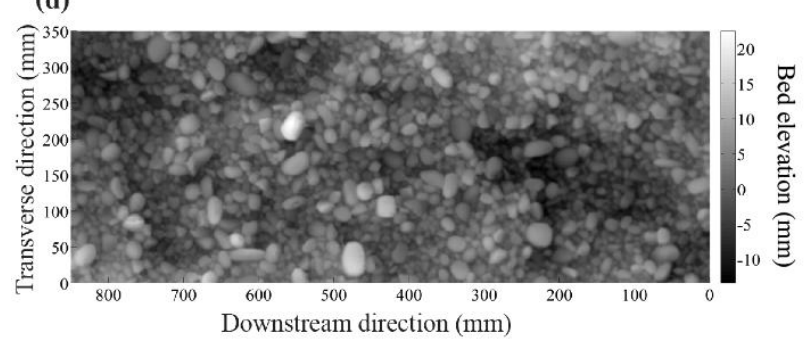

(b)

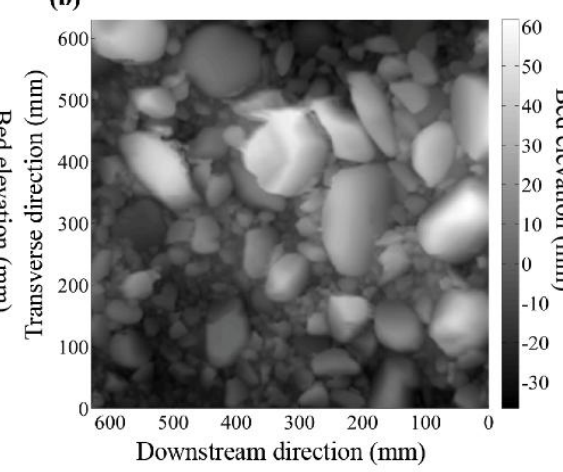

(e)

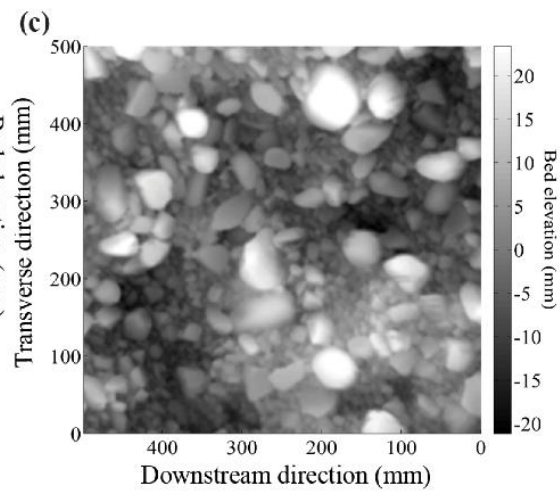

Downstream direction $(\mathrm{mm})$

164 Figure 2. Digital elevation models (DEMs) displaying the gravel-bed surfaces around the mean bed level, after flat-surface detrending, by removing the combined effect of bed slope and setup misalignment: (a) Field 1; (b) Field 2; (c) Field 3; (d) Lab 1 and (e) Lab 2. The surface forming flow direction is right to left.

To allow the accurate measurement of the bed-surface topography and grain structure with 169 digital photogrammetry for the five patches, a pair of Nikon D5100 cameras (16.4 Mpixel, $17023.6 \times 15.6 \mathrm{~mm}^{2}$ sensor size) with Nikkor $20 \mathrm{~mm}$ lenses, was installed in stereo (horizontal

171 baseline distance between cameras between 0.25 and $0.3 \mathrm{~m}$ ) vertically (i.e., both cameras

172 looking down, minimising occluded points which cannot be seen in one or the two images)

173 above the gravel beds. Presently, a variety of image-based DEM reconstruction techniques

174 are available, from the now conventional digital stereo (i.e. two-camera) photogrammetry,

175 using either commercial or non-proprietary calibration and stereo-matching engines, to novel

176 structure-from-motion (SfM) or multi-view stereo (MVS) photogrammetry (James and

177 Robson, 2012; Fonstad et al., 2013; Javernick et al., 2014) which does not need calibration.

178 However, a current drawback of SfM/MVS that may cause problems in recording a gravel 
179 patch at fine scales is the likely presence of large non-linear distortions in the DEMs, due to 180 inadequate lens distortion calibration (Fonstad et al., 2013; Ouédraogo et al., 2014), an issue 181 that has been resolved in traditional stereo photogrammetry (Wackrow and Chandler, 2008; 182 Bertin et al., 2015). Furthermore, as James and Robson (2012) show in their 3D measurement 183 of a volcanic bomb (surface $\sim 0.008 \mathrm{~m}^{2}$ ), a large number of photographs $(\sim 200$, of which $\sim 90$ 184 were processed for DEM reconstruction) are required to obtain a DEM with density 185 comparable to the DEMs obtained in the present study, which requires only two photographs.

186 The processing time to obtain one fine-scale DEM with SfM/MVS (12 hours) is thus very 187 long compared to the 15 minutes (stereo matching time) required by our approach.

188 The photogrammetric technique employed herein to obtain DEMs from stereo photographs 189 (i.e., two overlapping images as shown in Step 1, Figure 1) consists of (i) in-situ calibration, 190 using the method of Zhang (2000), included in Bouguet's (2010) open-access calibration toolbox for Matlab®, which requires several stereo photographs of a planar chequerboard to 192 be recorded to determine both intrinsic (i.e., camera) and extrinsic (i.e., setup) calibration 193 parameters; (ii) using the calibration data to accurately rectify (mean rectification error $<0.5$ 194 pixel and maximum error $<1$ pixel throughout the imaging area) stereo photographs of the 195 gravel beds to epipolar geometry, whereby corresponding pixels between overlapping images 196 are ideally on a same scanline (i.e., corresponding pixels have the same y-coordinate); (iii) scanline-based pixel-to-pixel stereo matching using Gimel'farb's (2002) symmetric dynamic 198 programming stereo (SDPS) algorithm, providing both point cloud data and ortho-images 199 (Step 2, Figure 1). Using the SDPS, occluded points are interpolated based on the assumption 200 of a continuous surface, leaving no voids. The careful design of the measurement setup (e.g., 201 adjusting the baseline and the camera height to the relief of the surface) helps to minimise 202 occlusions (Lane et al., 2000; Bertin et al., 2015); yet determining the proportion of occluded 203 points is not possible. To fulfil analytical requirements of regularly-spaced data (e.g., to 
measure bed-elevation structure functions) and to avoid bias introduced by non-uniform data when calculating the standard deviation of bed elevation $\sigma_{z}$ (Hodge et al., 2009a), point clouds were interpolated (using the triangle interpolation method in Matlab) onto regular grids (i.e., raster DEMs as shown in Step 3, Figure 1) with spacing $1 \mathrm{~mm}$ (the reference grid spacing against which other grids are compared, see Section 3). Each DEM underwent rigorous quality assurance testing (readers can refer to Bertin et al., (2015) and Bertin and 210 Friedrich (2016) where detailed evaluations of the laboratory and the field DEMs are 211 presented, respectively), to ensure surface metrics derived from the DEMs had minimum 212 effect due to DEM errors. Outliers, which accounted for less than 1\% of the DEM points, 213 were identified using the mean elevation difference parameter by comparing each DEM point 214 with its direct neighbours (Hodge et al., 2009b), and replaced using bi-cubic spline 215 interpolation. All DEMs were finally normalised to have a mean bed level equal to zero, and 216 rotated to be aligned with the surface-forming flow direction. Whilst flow direction 217 identification is straightforward for laboratory surfaces, the flow direction for field data was 218 determined by eye from observations of channel shape and grain imbrication (Laronne and 219 Carson, 1976; Millane et al., 2006; Bertin and Friedrich, 2016). Finally, using a least-squares 220 fit, flat-surface detrending was undertaken to remove the influence of both the bed slope and 221 experimental setup misalignments from the DEMs (e.g., Aberle and Nikora, 2006; Bertin and 222 Friedrich, 2016).

223 As shown in Table I, camera height could not be set constant throughout both the field and 224 the laboratory applications. The DEM characteristics therefore varied slightly between 225 applications; although DEM resolution and vertical error remained small compared to sediment size (cf. Table I), a precondition for grain roughness characterisation (Hodge et al.,

227 2009b). One can note that the laboratory DEMs have larger coverage, yet smaller pixel size 228 and theoretical vertical error. This is because the laboratory DEMs were obtained by merging 
229 three smaller overlapping DEMs, allowing shorter camera distance. We note that other 230 measurement techniques such as laser scanning (Hodge et al., 2009a, 2009b; Aberle and 231 Nikora, 2006) have been used by others to produce gravel-bed DEMs similar to the ones used 232 in this study.

233 Table I. Summary of the GSD information (both surface and subsurface where applicable) 234 and DEM characteristics, for the five gravel-bed patches. The subscript ' $A$ ' indicates surface 235 sediment from the armour layer, rather than the bulk sediment. The best DEM horizontal 236 resolution is the average pixel size on the gravel beds, which is also the average point spacing 237 in point clouds. The theoretical vertical error is estimated using classical photogrammetric 238 equations and depends on camera and lens specifications (i.e., sensor size, number of pixels 239 and focal length), as well as setup characteristics (i.e., baseline and camera distance). True 240 DEM accuracy (here the mean unsigned error) was estimated using a 3D-printed gravel-bed 241 model to be $0.43 \mathrm{~mm}$ and $0.67 \mathrm{~mm}$ in the laboratory and the field, respectively (cf. Bertin and 242 Friedrich, 2016).

\begin{tabular}{l|c|c|c|c|c}
\hline & FIELD 1 & FIELD 2 & FIELD 3 & LAB 1 & LAB 2 \\
\hline $\mathbf{D}_{\mathbf{5 0}}(\mathbf{m m})$ & N.A. & N.A. & N.A. & 8.4 & 9.2 \\
\hline $\boldsymbol{\sigma}_{\mathbf{G}}=\sqrt{\mathrm{D}_{84} / \mathrm{D}_{16}}$ & N.A. & N.A. & N.A. & 3.0 & 2.6 \\
\hline $\mathbf{D}_{\mathbf{5 0 A}}(\mathbf{m m})$ & 18.7 & 47.2 & 19.4 & 18.9 & 18.5 \\
\hline $\mathbf{D}_{\mathbf{9 0 A}}(\mathbf{m m})$ & 27.3 & 104.7 & 47.7 & 27.1 & 28.1 \\
\hline $\boldsymbol{\sigma}_{\mathbf{G A}}=\sqrt{\mathrm{D}_{84 \mathrm{~A}} / \mathrm{D}_{16 \mathrm{~A}}}$ & 1.4 & 2.2 & 2.3 & 1.4 & 1.4 \\
\hline Patch size $(\mathbf{m m})$ & & & & & \\
$($ downstream $\times$ & $600 \times 500$ & $630 \times 630$ & $500 \times 500$ & $850 \times 350$ & $850 \times 350$ \\
transverse) & & & & &
\end{tabular}




\begin{tabular}{|c|c|c|c|c|c|}
\hline $\begin{array}{l}\text { Normalised patch } \\
\text { size by } D_{50 A} \\
\text { (downstream } x \\
\text { transverse) }\end{array}$ & $32 \times 26$ & $13 \times 13$ & $25 \times 25$ & $45 \times 18$ & $45 \times 18$ \\
\hline $\begin{array}{l}\text { Best DEM } \\
\text { horizontal } \\
\text { resolution }(\mathrm{mm})\end{array}$ & 0.20 & 0.22 & 0.19 & 0.17 & 0.16 \\
\hline $\begin{array}{l}\text { Theoretical vertical } \\
\text { error }(\mathrm{mm})\end{array}$ & 0.55 & 0.59 & 0.47 & 0.36 & 0.36 \\
\hline $\begin{array}{l}\text { Approximate } \\
\text { camera distance } \\
(\mathrm{mm})\end{array}$ & 825 & 860 & 765 & 675 & 670 \\
\hline
\end{tabular}

243 Grain-size distributions (GSDs)

244 To complement topographic information derived from DEMs and to allow comparison with

245 sediment size, the bed-surface composition based on the sediment grains' intermediate axis

246 was determined for each gravel patch using a single vertical photograph (number of detected

247 grains $>400$ ) and the image-analysis tool Basegrain $®$. The latter allows for automatic grain

248 separation in digital images of gravel beds and applies the Fehr's (1987) line-sampling 249 method for results' analysis (Detert and Weitbrecht, 2012). Independent measurements were 250 obtained by measuring surface sediment along lines with a digital calliper (with results 251 presented in Stähly et al., (2017)), which allowed us to calibrate the results obtained with 252 Basegrain. 
253 In addition to surface composition determined with Basegrain, the experimental sediment 254 mixtures used in the laboratory were sieved to determine the sediment grading curves (Table

255 I), particle shape and specific gravity. To distinguish GSDs of the bed surface from those of 256 the bulk mixtures, percentiles derived from GSDs were indexed with " $\mathrm{A}$ " to represent 257 characteristics of the armoured surface.

\section{Grid spacing and the effect of DEM horizontal resolution}

259 To quantify the effect of DEM resolution or grid spacing on the roughness information 260 derived, point clouds of the five patches were transformed into DEMs of varying resolution 261 by interpolating the raw elevation data (using triangle interpolation in Matlab) from point 262 clouds on regular grids (Step 3, Figure 1) with spacing: $0.35 \mathrm{~mm}, 0.5 \mathrm{~mm}, 1 \mathrm{~mm}$ (the 263 reference grid spacing), $3 \mathrm{~mm}, 10 \mathrm{~mm}, \mathrm{D}_{50 \mathrm{~A}}$ and $2 \times \mathrm{D}_{50 \mathrm{~A}}$ (i.e., spacing equal to the surface 264 median grain size and two times the surface median grain size, respectively). The decision on 265 the grid spacings used herein was guided by grid spacings used in the literature (as presented 266 in the background section), as well as to enable investigation of a threshold grid size 267 decoupled from sediment size (here $\mathrm{D}_{50 \mathrm{~A}}$, as this is the property most commonly reported). .

\section{Surface metrics and the moving-window analysis}

269 To quantify the character and surface variability of the five patches, six surface metrics (see

270 Table II) were calculated for each DEM within moving windows of different sizes. In 271 reporting our results on moving windows, we distinguish the term DEM size from the size of 272 the gravel patch measured (Table I); in that DEM size is varied by adjusting the size of the 273 moving windows. The maximum window size tested is necessarily less than the patch size.

274 Square windows were used (in comparison to circular windows as in Scown et al., 2015), 275 since recorded DEMs are more often square (or rectangular) in shape. The effect of the 
measurement orientation (in the case of rectangular DEMs) was also examined. For this, the

277 initially square windows were halved either horizontally or vertically to form rectangular

278 windows with their long axis aligned either parallel or perpendicular to the flow direction. To

279 facilitate observations from the graphs and to allow comparison between the five patches

280 studied, window size in both directions was normalised by $\mathrm{D}_{50 \mathrm{~A}}$ (i.e., calculations were made

281 within windows with an area proportional to the area covered by the surface $\mathrm{D}_{50 \mathrm{~A}}$ determined

282 over the whole DEM). Surface metrics were obtained for each window of the designated size,

283 whilst windows are moved across the whole surface of the DEM (Step 4, Figure 1), with the

284 number of windows fitting into the DEM ranging from $>2000$ (at small window sizes) to $<50$

285 (at larger window sizes). An overlap between moving windows of 95\% of the window size

286 was used, except for calculating structure functions, for which a $25 \%$ overlap was used due to

287 the very large computational demand (still, a typical run time was 24 hours per DEM).

288 Sensitivity analysis of the effect of changing the overlap size to $25 \%$ showed no adverse

289 effect interpreting the findings. However, a 95\% overlap was preferred when possible due to

290 refined visual presentations of the results across window sizes (i.e., smoother graphical lines).

291 The commonly used surface metrics calculated from bed-elevations used in this study are

292 presented in Table II. Bed-elevation distribution moments contained in probability 293 distribution functions (PDFs) include $\sigma_{z}, S_{K}$ and $K_{u}$ and are classic descriptors of bed 294 roughness used in a number of studies at scales ranging from grain size to channel shape 295 (e.g., Aberle and Nikora, 2006; Scown et al., 2015). Surface variability about the mean 296 elevation within an area is indicated by $\sigma_{z}$ (Eqn. 2) and represents a characteristic vertical 297 roughness scale of the bed surface, which can be used as a grain-roughness parameter in flow 298 resistance equations (Aberle and Smart, 2003; Noss and Lorke, 2016). Skewness ( $S_{K}$, Eqn. 3) 299 describes the degree of asymmetry of the PDF and can be used to assess the general shape of 300 the bed surface. In this regard for water-worked gravel beds, a positive skewness is attributed 
to finer grains filling depressions and reducing the magnitudes of surface deviations below mean bed level (Aberle and Nikora, 2006). Kurtosis ( $K_{u}$, Eqn. 4) provides a measure of the regularity or intermittency of the bed. A distribution characterised by heavy tails and a 304 narrow peak has a large kurtosis, with more of the variance due to infrequent extreme 305 deviations. More uniform and compact distributions, of frequent modestly sized deviations 306 from the mean, are of lower kurtosis values (Coleman et al., 2011).

307 Table II. Surface metrics calculated from gravel-bed elevations used in this study.

\begin{tabular}{|c|c|c|}
\hline Parameter & Formula & Equation \\
\hline $\begin{array}{l}\text { Standard } \\
\text { deviation } \\
\left(\sigma_{z}\right)\end{array}$ & $\sigma_{z}^{2}=\frac{1}{N^{\prime}} \sum_{i=1}^{N^{\prime}}\left(Z_{i}-\left\langle Z_{i}\right\rangle\right)^{2}$ & (2) \\
\hline $\begin{array}{l}\text { Skewness } \\
\left(S_{K}\right)\end{array}$ & $S_{k}=\frac{1}{N^{\prime} \sigma_{z}^{3}} \sum_{i=1}^{N^{\prime}}\left(Z_{i}-\left\langle Z_{i}\right\rangle\right)^{3}$ & (3) \\
\hline $\begin{array}{l}\text { Kurtosis } \\
\left(K_{u}\right)\end{array}$ & $K_{u}=\left[\frac{1}{N^{\prime} \sigma_{Z}^{4}} \sum_{i=1}^{N^{\prime}}\left(Z_{i}-\left\langle Z_{i}\right\rangle\right)^{4}\right]-3$ & (4) \\
\hline $\begin{array}{l}\text { Structure } \\
\text { function } \\
\left(D_{G 2}\right)\end{array}$ & $D_{G 2}(\Delta x, \Delta y)=\frac{1}{(N-n)(M-m)} \sum_{i=0}^{N-n} \sum_{j=0}^{M-m}\left\{\left|z\left(x_{i}+n \delta x, y_{j}+m \delta y\right)-z\left(x_{i}, y_{j}\right)\right|\right\}^{2}$ & (5) \\
\hline $\begin{array}{l}\text { Inclination } \\
\text { index }(I 0)\end{array}$ & $I O=\frac{n_{+}-n_{-}}{N s}$ & (6) \\
\hline
\end{tabular}

309 points and $<>$ represents the mean value. $\Delta x=n \delta x$ and $\Delta y=m \delta y ; \delta x$ and $\delta y$ are the sampling 310 intervals (i.e., DEM resolution) in the longitudinal and transverse directions respectively; 
$311 n=1,2,3, \ldots N$ and $m=1,2,3, \ldots M . N$ and $M$ are the number of DEM points in the same two

312 directions. $n_{+}$and $n_{-}$are the number of positive and negative slopes between successive DEM

313 points, respectively, and $N s$ is the total number of slopes.

314 Horizontal roughness lengths in both the streamwise and the cross-stream direction $\left(L_{x}\right.$ and

$315 L_{y}$, respectively) are scaling characteristics of a surface and are calculated from second-order

316 structure functions (Eqn. 5).

317 Structure functions, which are different from semivariograms by a factor two, measure 318 changes in elevation correlations at different spatial lags and in different directions (Figure

319 3). Small structure function values represent regions characterised by similar elevations

320 (because of DEM points located on a same grain or bedform), while large values identify 321 regions on a surface that are not correlated anymore. A gravel-bed elevation structure 322 function has three regions: a scaling region with uniform slope at small lags, a saturation 323 region at large lags, where the slope is zero, with a transition region in between, where the 324 slope decreases (Nikora et al., 1998; Hodge et al., 2009a). As shown in Figure 3, the scaling 325 region of the 1D structure function fitted with a power law, provides information about the 326 horizontal roughness lengths $L_{x}$ and $L_{y}$, which are determined from the slope breakpoint, 327 located at the intersection between the tangent to the scaling region slope and the saturation 328 level asymptote, in both $\mathrm{x}$ and y directions (Nikora et al., 1998). Hence, $L_{x}$ and $L_{y}$ were 329 calculated from 1D structure functions whereby $\Delta x=0$ and $\Delta y=0$, respectively. The 330 maximum spatial lag to calculate $D_{G 2}$ (Eqn. 5) in both $x$ and $y$ directions was chosen as half 331 the window size in the same two directions, and $L_{x}$ and $L_{y}$ were determined at the condition 332 the saturation region was attained for all moving windows of the same size. 


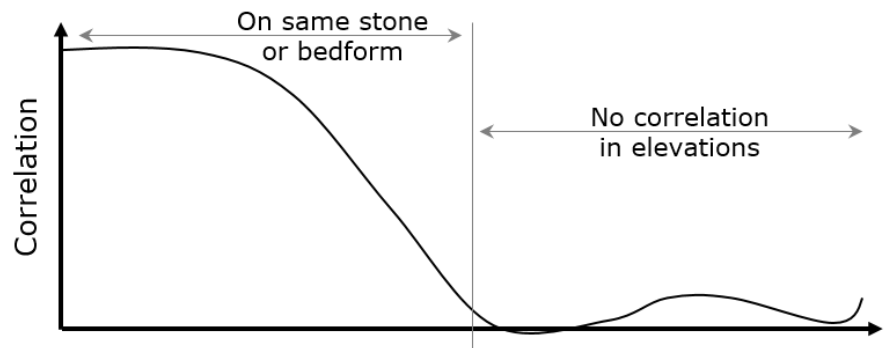

I = lag distance between DEM points

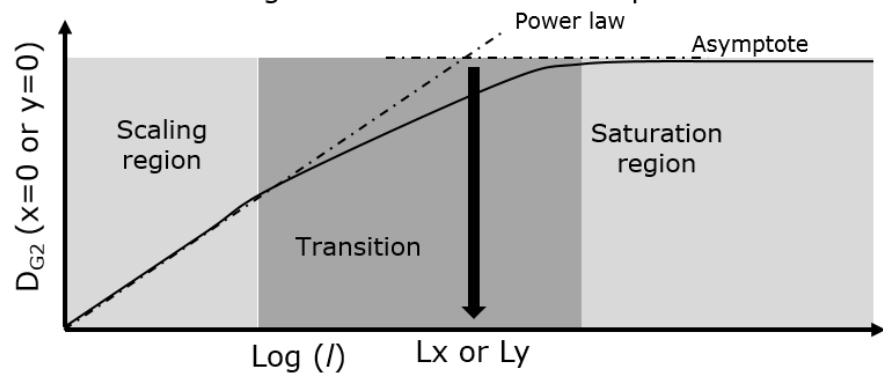

334 Figure 3. Typical gravel-bed elevation correlation and structure function graph for different

335 spatial lags, used to determine horizontal roughness lengths $L x$ and $L y$. Adapted from Smart

336 et al. (2002).

337 The inclination index (IO) in the flow direction is calculated using Eqn. 6 (Smart et al. 2004).

338 It analyses the signs of elevation changes between successive pairs of DEM points on 339 transects aligned with the flow direction at a lag distance equal to the DEM resolution, where

340 a positive slope refers to increasing bed elevations downstream. Slopes whose absolute value

341 is below 0.01 were deemed not reliable (i.e., neither positive nor negative), and were

342 therefore not counted in the numerator of Eqn. 6 (Millane et al., 2006). A positive inclination

343 index reflects the dominance of positive slopes and thus particle imbrication, generally

344 maximum in the flow direction, minimum in the direction opposite to the flow, and

345 approximately zero in a direction transverse to the flow (Laronne and Carson, 1976; Millane

346 et al., 2006). Characterising grain imbrication is therefore relevant for determining flow

347 direction from bed-surface analysis, but also provides insights on bed stability and the history

348 of the flow that shaped the surface. 
349 The surface variability for the six surface metrics was also quantified with the coefficient of 350 variation $(\mathrm{CV})$, calculated as the standard deviation of the property determined over all 351 moving windows divided by the mean, and expressed as a percentage. To study the effect of 352 measurement scale on surface variability, CV was calculated for different window sizes.

\section{Results}

354 Because the respective effects of DEM size and grid spacing on roughness parameters cannot 355 be presented collectively, examination is undertaken step-by-step. We start with the effect of 356 DEM size and first examine the spatial variability of roughness parameters using moving 357 windows. Only window size is altered during this first part of the analysis, while generic grid 358 spacing is maintained (i.e., grid spacing equal to the reference value of $1 \mathrm{~mm}$ ).

\section{Roughness Spatial Variability}

360 Figure 4 presents the coefficient of variation (CV) for all roughness parameters and gravel 361 patches considered in this paper with changes in moving-window size. As is common 362 practice, $\mathrm{CV}$ was used at the condition of positive property values only. Here, the surface 363 metrics $S_{K}$ and $I 0$ sometimes adopt negative values when calculated over small window sizes, 364 whilst positive values (characteristic of a water-worked and imbricated gravel bed) are 365 measured for all patches at larger window sizes. Therefore, calculation of CV for $S_{K}$ and $I 0$ 366 required adjustments in the range of window sizes, as shown. Despite this caveat, two 367 observations can be obtained from Figure 4. Firstly, there are differences in the spatial 368 variability of certain roughness parameters. Particularly evident are the higher CV values at a 369 given window size, in both skewness and inclination index, an indication that these two 370 parameters vary widely spatially within a gravel patch. Across all DEMs, the parameters

371 which provided the lowest $\mathrm{CV}$ values (reaching a minimum of below 5\%), were horizontal 372 roughness lengths $L_{x}$ and $L_{y}$, along with $\sigma_{z}$ (Figure 4). Secondly, spatial variability for the 
373 majority of roughness parameters declines with increases in moving-window size, until it

374 plateaus out. This observation suggests the existence of a threshold DEM size, evaluated

375 hereinafter, above which the surface roughness of the patch is characterised by the parameters

376 and decision on the location of the DEM within the patch is becoming less important (Scown

377 et al., 2016).

378 For the rest of the analysis, not all roughness parameters are presented, but instead horizontal

379 roughness lengths, $\sigma_{z}$, and $I 0$ are chosen to exemplify trends representative of all roughness

380 parameters. The selection comprises roughness parameters commonly used for gravel beds

381 and as shown in Figure 4, encompasses parameters with a wide range of spatial variability,

382 therefore maximising the representativeness of the findings. 
Field 1

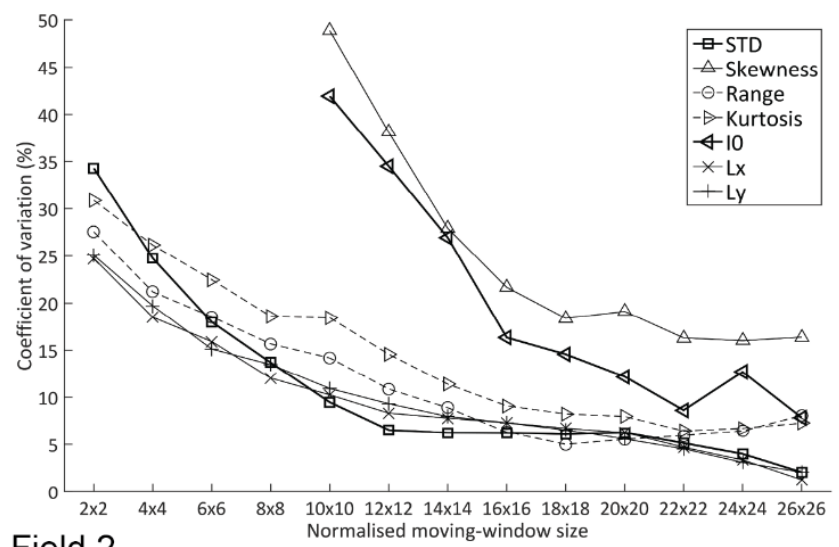

Field 2

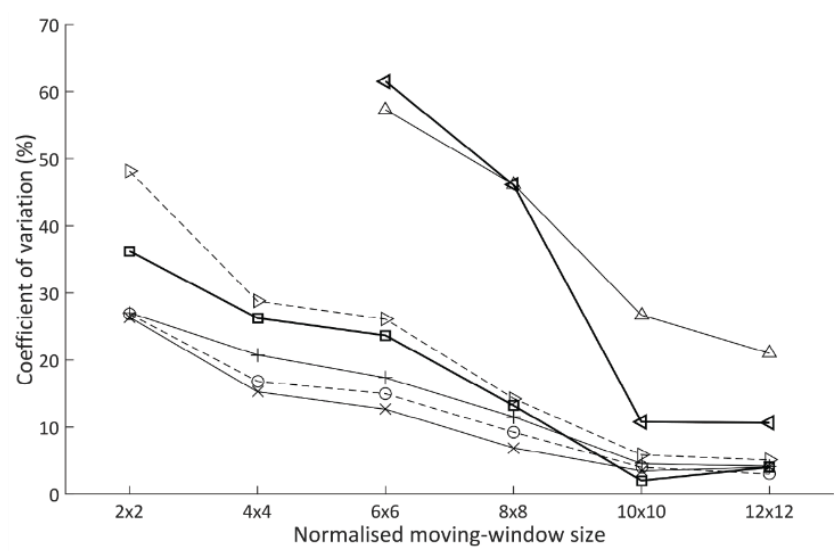

Field 3

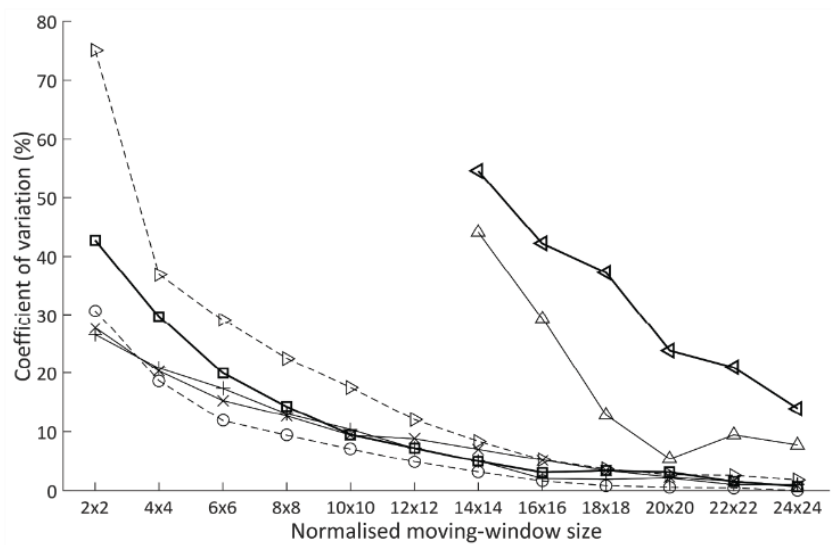

Figure 4. Coefficient of variation (CV) for all roughness parameters, for all datasets (Field

385 DEMs left column, Lab DEMs occupy the right column), calculated at different moving-

\section{Effects of DEM size and Orientation on Roughness Parameterisation}

388 Figure 5 displays the coefficient of variation $(\mathrm{CV})$ in $\sigma_{z}$ for all five datasets. Previously, we

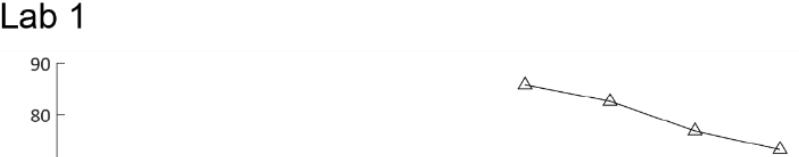

Lab 2

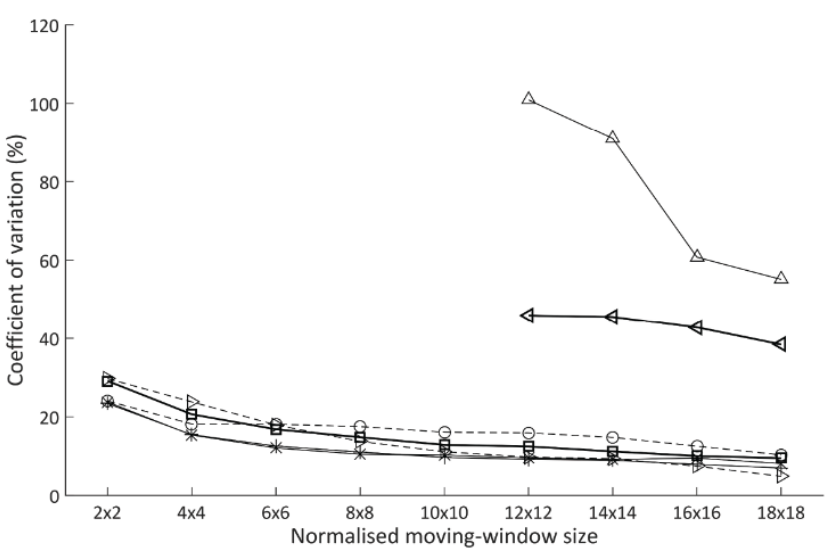

window sizes normalised in both directions by $\mathrm{D}_{50 \mathrm{~A}}$. observed a consistent decrease in spatial variability with window size increases for all 
roughness parameters studied (Figure 4). Focusing on one parameter now enables examination of whether a threshold DEM size represented by a plateau in variability exists,

392 as well as to examine the effect of patch orientation.

393 Figure 5 confirms a clear effect of window (hence DEM) size on the roughness statistics, for 394 all patches. The smaller the moving-window size, the larger the variance in results produced 395 across the patch. Variance reduces and plateaus as the window size increases, between 12 and $39618 \times \mathrm{D}_{50 \mathrm{~A}}$ across the majority of the patches. However, there are patches showing a further 397 decrease in variance following this observed plateau (Figures 5a and 5c). Given bedforms 398 were not filtered from DEMs for this analysis; we believe this observation suggests two 399 spatial scales of surface roughness present.

400 Across all patches the size of the window (hence DEM size) has a greater control on 401 roughness statistics than the orientation of the window. Similarities in statistics exist 402 regardless of the orientation (shape) of the window, apart from Field 2 (Figure 5b), where 403 vertical windows result in lower CV, and Lab 1 (Figure 5d), where CV is higher for vertical 404 windows and lower for horizontal windows compared to the use of square windows. These 405 differences suggest surface anisotropy in the flow direction for Lab 1, whilst Field 2 is 406 characterised by higher variability in $\sigma_{z}$ in the transverse direction. 

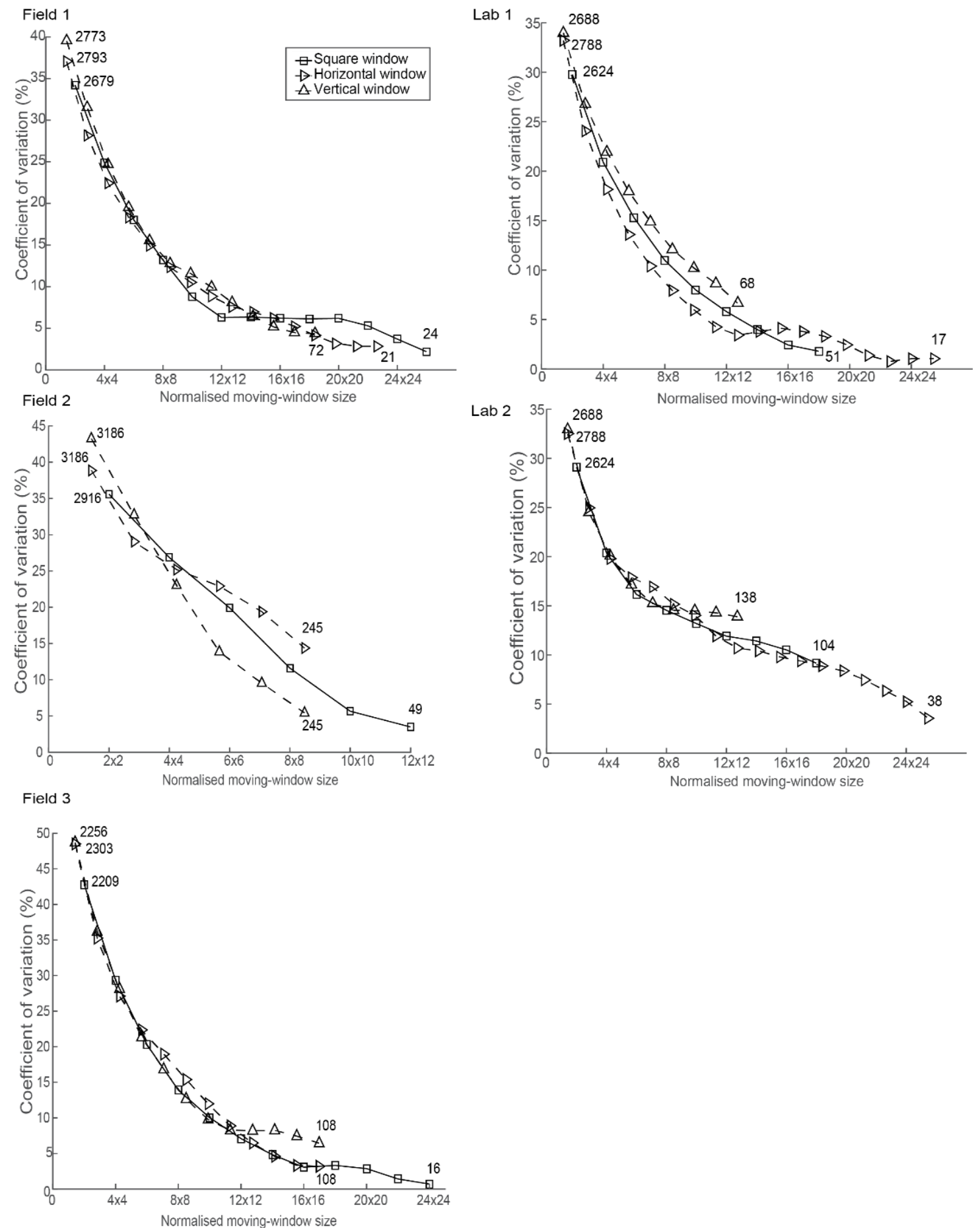

408 Figure 5. Coefficient of variation $(\mathrm{CV})$ in $\sigma_{z}$ for all datasets (Field DEMs left column, Lab 409 DEMs occupy the right column), calculated at different moving-window sizes normalised in 410 both directions by $\mathrm{D}_{50 \mathrm{~A}}$. The number of windows generated for the maximum and minimum 411 sizes are provided on the graphs. 
412 Boxplots obtained using the moving-window analysis technique are presented in Figure 6, for

$413 \sigma_{z}$, which demonstrate trends that are apparent across roughness parameters (Figure 4).

414 Supplementing the analysis of roughness spatial variability using CV (Figures 4 and 5),

415 boxplots enable examination of the evolution of the median value of a roughness parameter

416 with window size increases. For roughness statistics calculated at small window sizes, the

417 variability was larger than that at larger window sizes (Figure 6), which echoes previous

418 observations using CV (Figures 4 and 5). Visually both the median values and the variability

419 in statistics (e.g., boxplot whiskers) plateau between $14-18 \times \mathrm{D}_{50 \mathrm{~A}}$ for all patches (Figure 6).

420 These plateaus were confirmed statistically using 95\% confidence intervals and a paired t-

421 test. The plateaus indicate the window (hence DEM) size is adequately detecting the

422 topographic information under the scale of interest. Figures 5 and 6 suggest once the DEM

423 size exceeds between $16-18 \times \mathrm{D}_{50 \mathrm{~A}}$ in both directions in the field DEMs, and smaller sizes

424 between $14-16 \times \mathrm{D}_{50 \mathrm{~A}}$ in the laboratory, information derived from DEMs is deemed to

425 provide a suitable indication of the overall surface roughness with little effect due tosurface

426 variability. Noticeably, Field 2 (Figures 5 b and 6 b) began to plateau at smaller window sizes

$427\left(10-12 \times \mathrm{D}_{50 \mathrm{~A}}\right)$ than the other two field DEMs. However, Field 2 was the patch examined

428 with the coarsest sediment and the smallest normalised patch size (Table I), which may

429 impede effective plateau identification. 

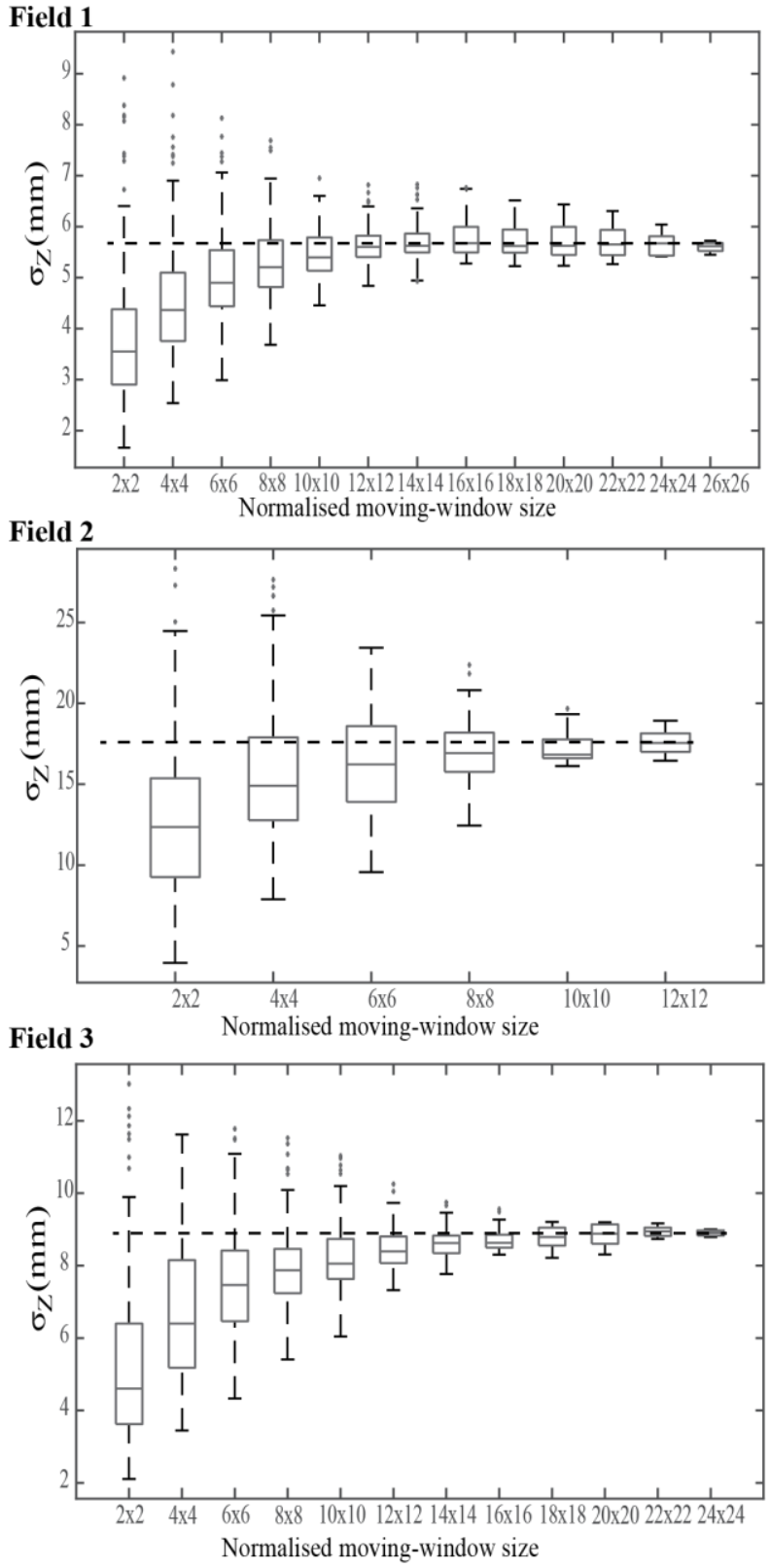
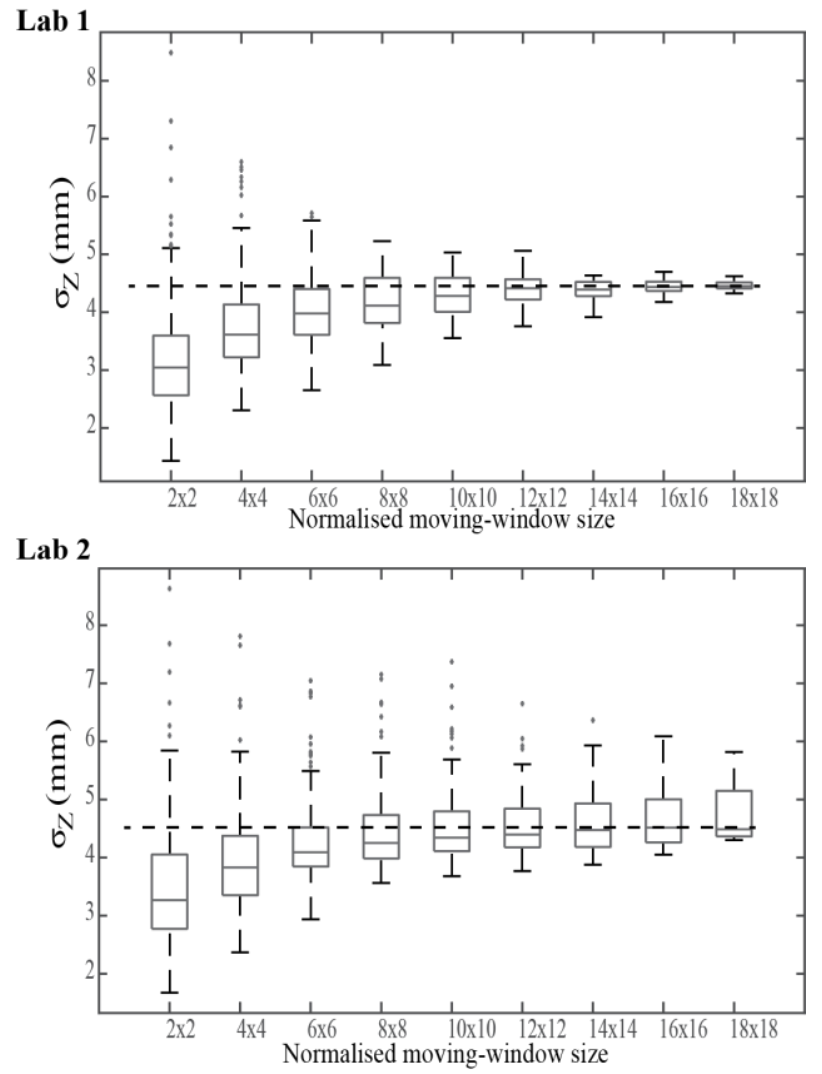

431

432

Figure 6. Standard deviation of bed elevations $\left(\sigma_{z}\right)$ for all datasets, (Field DEMs left column,

433 Lab DEMs occupy the right column), calculated at different moving-window sizes

434 normalised in both directions by $\mathrm{D}_{50 \mathrm{~A}}$. Horizontal line in the boxplot represents the median

435 value for each DEM size and whiskers display the variability in results. Dashed lines were added to help visualise the plateauing in $\sigma_{z}$ with window size increases. 
438 Figure 7 presents results of varying DEM grid spacing on two roughness statistics, $\sigma_{z}$ and $I 0$,

439 which have been chosen to reflect the patterns observed across parameters (Figure 4). For this

440 analysis, only grid spacing was varied, whilst parameters were calculated over the complete

441 DEM size (i.e., patch size).

442 Figure 7 shows minimal differences between using a $0.35 \mathrm{~mm}$ and a $1 \mathrm{~mm}$ grid spacing,

443 which was observed across all patches. $1 \mathrm{~mm}$ corresponds to the size of the smallest surface

444 grains identified in this study, which also corresponds to a ratio of between 1 to 20 and 1 to

44550 when compared with $\mathrm{D}_{50 \mathrm{~A}}$ (cf. Table I). For this reason, it is preferred presenting small

446 grid sizes in absolute values (i.e., not normalised by $\mathrm{D}_{50 \mathrm{~A}}$ ). Figure 7 a displays stable $\sigma_{z}$ with

447 changes to grid spacing exceeding $1 \mathrm{~mm}$, up to a grid size equal to $\mathrm{D}_{50 \mathrm{~A}}$, for all patches, apart

448 from Field 2, which displays differences at a grid spacing equally the $\mathrm{D}_{50 \mathrm{~A}}$ value. However,

449 there are evident differences in inclination index $(I 0)$ at the coarser spacing, with grid spacing

450 exceeding $1 \mathrm{~mm}$ providing fluctuating values, generally negative, and therefore unable to

451 detect surface grain imbrication. This echoes previous observations of $I 0$ (and skewness)

452 being more variable spatially within a patch than $\sigma_{z}$ (Figure 4), and thus requires smaller grid 453 spacing for roughness characterisation. 
(a)

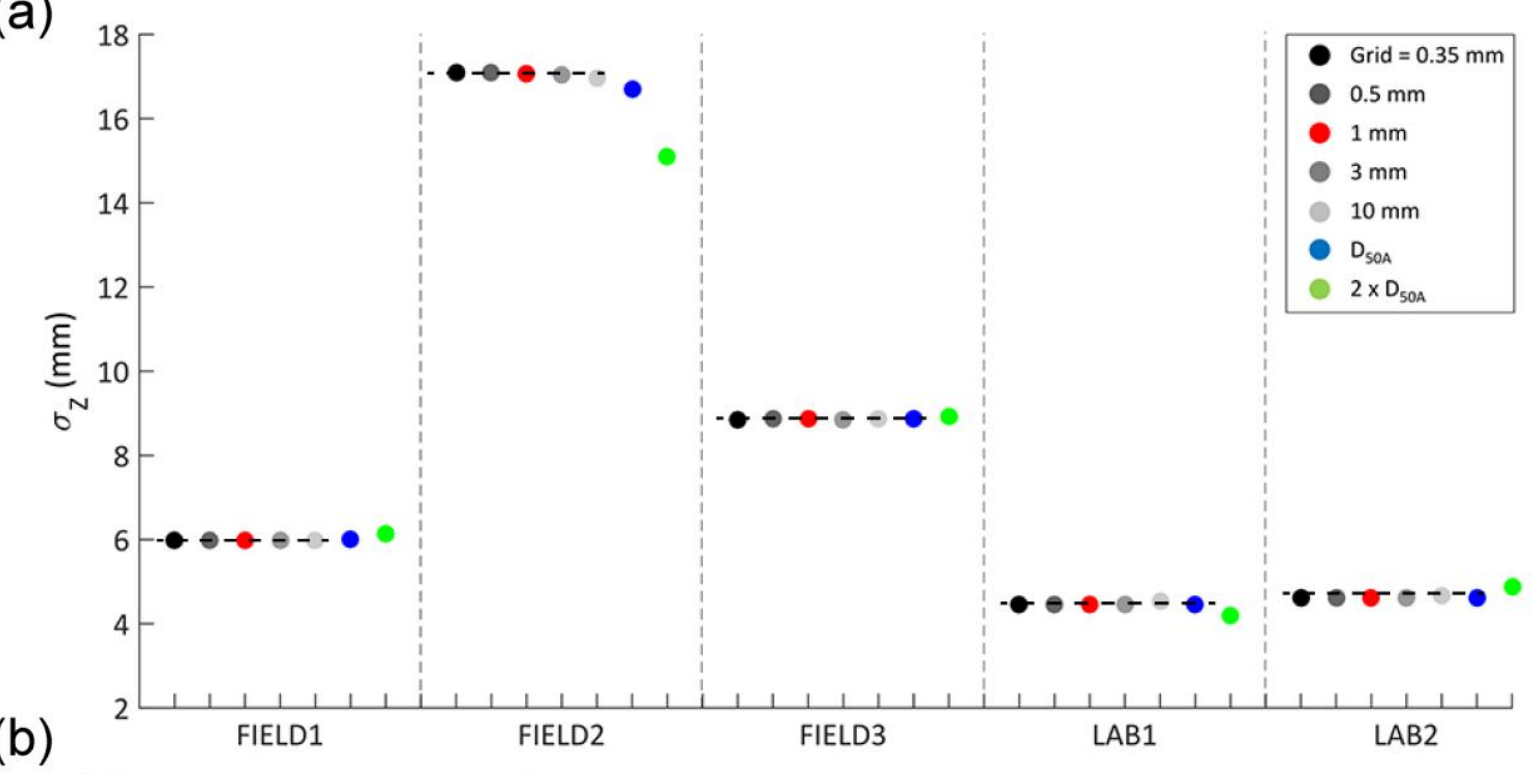

(b)

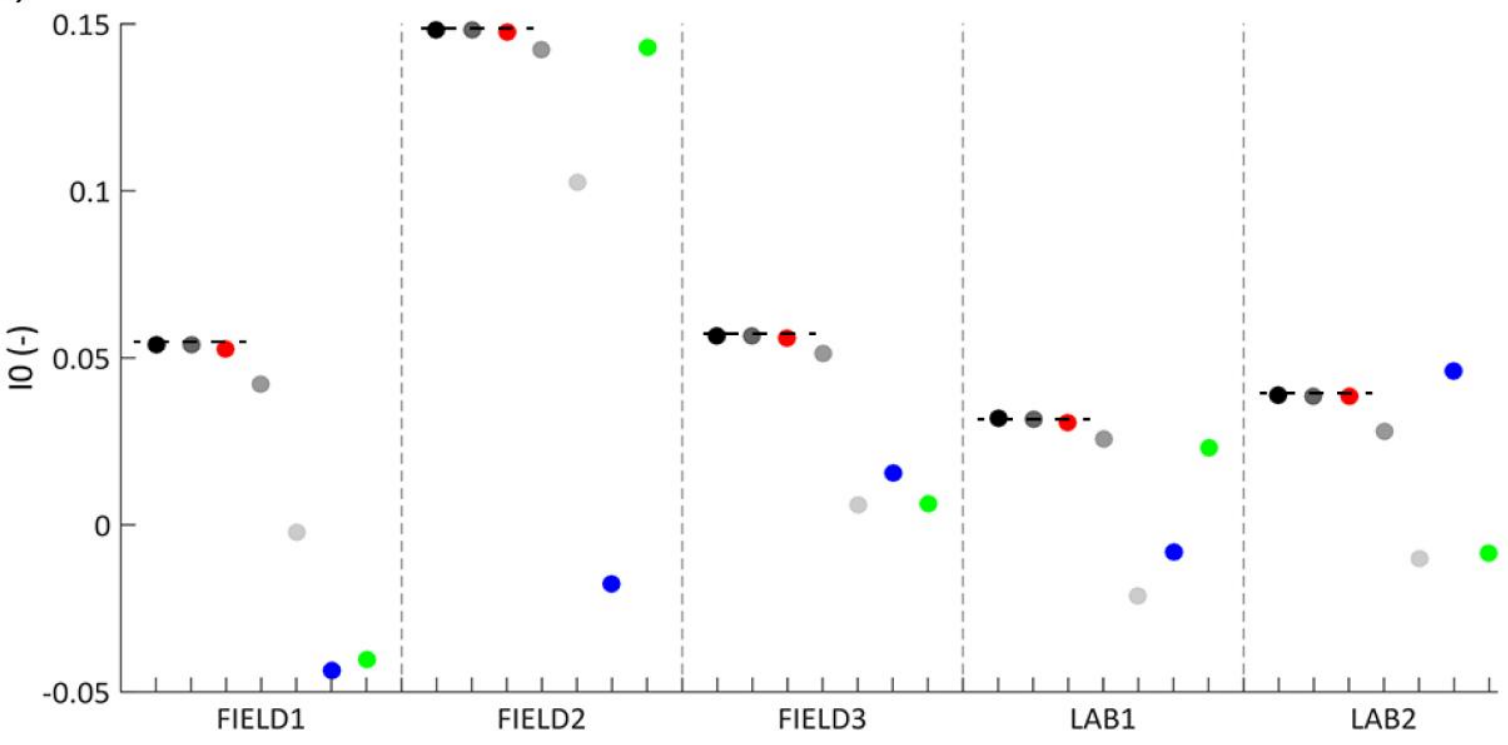

455 Figure 7. The effect of grid spacing for all datasets on the (a) standard deviation $\left(\sigma_{z}\right)$ and (b)

456 inclination index in the flow direction (IO). The selection of the two surface metrics was

457 based on the consideration that $\sigma_{z}$ and $I O$ encompass the patterns observed over all 458 parameters. Horizontal lines were added to help visualise the similarities in data points. $\mathrm{D}_{50 \mathrm{~A}}$ 459 values are presented in Table I. 
462 Previous studies using gravel-bed DEMs for roughness parameterisation often differ in terms

463 of the DEM size and grid spacing used for analysis. Common to all studies however, is the 464 assumption that parameters derived from DEMs are reliable measurements of the surface. We 465 show that accounting for spatial variability of the surface is important, as it has implicit 466 connections with analytical requirements (e.g., the required DEM size and grid spacing).

467 In this study, we have quantified spatial variability in roughness parameters to provide deeper 468 insights into the fundamentals required for DEM analysis. Novel results obtained show that 469 spatial variability in roughness parameters exists across a gravel patch, as processes shaping 470 alluvial beds naturally result in surface heterogeneity at all scales (e.g., Graham et al., 2010; 471 Nelson et al., 2014; Scown et al., 2015). This complements previous observations of spatial 472 variability in sediment size. Besides, we show that roughness parameters differ greatly on 473 their degree of spatial variability within a patch (e.g., the vertical shift between roughness 474 parameters shown in Figure 4).

475 Roughness parameters with the lowest and most consistent variance over window size 476 increases (e.g., horizontal roughness lengths and $\sigma_{z}$ ) are deemed the parameters adequate to 477 provide robust measures of roughness over a patch. However, certain roughness parameters 478 display high variance (e.g., skewness), with fluctuations in this parameter reflecting spatial 479 variability in particle arrangement (Aberle and Nikora, 2006). Similarly, large fluctuations in 480 inclination index for a given window size indicate heterogeneous grain imbrication (Figure $4814)$. 
483 Although differing in their degree of spatial variability, all roughness parameters examined 484 show a consistent reduction in spatial variability with window size increases (Figure 4). Thus, 485 one can use measurements of spatial variability to identify a suitable DEM size that ensures 486 roughness parameters independent of the surface heterogeneity (e.g., Scown et al. 2015, 487 2016). A similar approach was used by Graham et al. (2010) to determine a suitable 488 measurement size for maximising the accuracy of image-based grain size measurements.

489 Figure 5 shows a greater control of window size (hence DEM size) on roughness statistics 490 than the orientation (shape) of the window. Overall, we deem the orientation of 491 measurements to not have a clear influence on the roughness statistics, unless the surface is 492 clearly anisotropic. Therefore we suggest using square moving windows for analysis of 493 gravel bed spatial variability, in order to reduce the effect of anisotropy.

494 Our findings of a reduction in CV with increases in window size (Figures 4 and 5) are in line 495 with a field-based study of roughness length and bed shear stress in a coarse-bed channel, 496 which found reduced CV with an increase in sample size (i.e., an increased number of 497 samples collected over an increased spatial coverage) (Cienciala and Hassan, 2016). Once a 498 certain DEM size is reached, at which grain-roughness information is measured, CV may 499 reduce again due to the presence of bedforms or larger scale roughness elements (Figure 5). 500 This supports the theory of gravel patches displaying mixed-fractal behaviour with two scales 501 of roughness, whereby bedform roughness is represented by a fractal band exceeding the 502 largest grains (Robson et al., 2002; Aberle and Nikora, 2006; Bergey, 2006; Qin and Ng, 503 2012; Noss and Lorke, 2016). Although CV reduces following a plateau, gravel patches 504 display variance continually due to the lack of uniformity in the nature of a gravel-bed 505 surface. This lack of uniformity leads to topographic variability both within and between 
506 patches analysed in this study, due to differences in sorting, packing, burial, imbrication, 507 shape and size of the sediment (Graham et al., 2010).

508 The plateau in variance observed in the field DEMs occurred at larger sizes, which we

509 believe is due to poorly sorted sediment (Table I) and the increased prevalence of small-scale

510 bedforms in the field (seen in Figure 2). Bedforms can contribute to an increased surface 511 complexity in comparison to the more uniform laboratory DEMs, with variance plateauing at 512 smaller sizes (Bertin and Friedrich, 2016).

513 As mentioned previously, plateaus were observed when the median values become stable and 514 variability remains consistent as window size increases further (Figures 5 and 6). These 515 observed plateaus were confirmed statistically, using 95\% confidence intervals to assess 516 variability (also used in work by Cienciala and Hassan (2016) to assess spatial variability in 517 data relating to sample size) and a paired t-test to assess for statistical differences between 518 mean values for the data at each moving-window size. The statistical confirmation used both 519 methods, as in some parameters the median values plateaued, however variability fluctuated, 520 and observed thresholds considered both of these factors to be stable for estimation of an 521 appropriate DEM size. Therefore, in certain roughness parameters, such as skewness and $\sigma_{z}$ 522 in Field 2, a plateau was not observed, possibly due to a small DEM size compared to $\mathrm{D}_{50 \mathrm{~A}}$ 523 and high spatial variability across the surface.

\section{Grid spacing}

525 A previous study by Scown et al. (2015), investigating the effect of DEM size on floodplain 526 topography did not consider the effect of grid spacing on the outputs. In contrast, we find grid 527 spacing to have an effect on roughness statistics (Figure 7).

528 The lack of differences between $0.35 \mathrm{~mm}$ and $1 \mathrm{~mm}$ grid spacing for all roughness 529 parameters measured in this study (Figure 7), suggests these grid spacings are adequately 
530 capturing the grain roughness for a range of sediment size $\left(\mathrm{D}_{50 \mathrm{~A}}=[19-47 \mathrm{~mm}]\right)($ Hodge et

531 al., 2009a; Hodge et al., 2009b). Throughout our DEM size analysis a grid spacing of $1 \mathrm{~mm}$

532 was used, as this is already degraded from a point spacing of $\sim 0.2 \mathrm{~mm}$ in point clouds (Table

533 I) and provided the best DEM quality results we could obtain, with reasonable efficiency.

534 Furthermore, this is the grid spacing that other researchers have used (Hodge et al., 2009a;

535 Curran and Waters, 2014; Bertin et al., 2017).

536 Exceeding the $1 \mathrm{~mm}$ grid spacing affects the results, suggesting using these resolutions do not

537 provide suitable grain-roughness statistics and even induce errors (Milenković et al., 2015).

538 The differences in values observed at these grid spacings is due to complex surface

539 topography being lost, or the spatial variability of the surface being non-identifiable

540 (Buffin- Bélanger et al., 2006; Hodge et al., 2009a). Previous studies have found that using a

541 coarser grid spacing of $5 \mathrm{~mm}$ prevented the identification of the spatial variability of a

542 sediment surface (Buffin- Bélanger et al., 2006). For example, coarser grid spacing may pick

543 up bedform roughness, reflecting the variability between humps and hollows of bedforms,

544 and warping the grain-scale statistics. These differences at larger grid spacing are particularly

545 evident in inclination index (Figure 7b) with values of 0 or negative, which indicates there is

546 no imbrication of sediment grains. This suggests larger grid spacing does not identify grain

547 imbrications that are observed for resolutions below $3 \mathrm{~mm}$.

\section{Implications of the research}

\section{Measurement of roughness spatial variability to explain surface processes}

550 Assessing spatial variability of a gravel-bed surface is of importance to studies investigating

551 the interactions between sediment and flow, for instance to explain measured spatial 552 differences in sediment transport (Haschenburger and Wilcock, 2003; Casas et al., 2010).

553 Using patch-scale DEMs and a moving-window technique, we were able to show that using 
554 parameters such as $\sigma_{z}$ and roughness lengths from structure functions, although provide stable 555 measures of roughness, may be inappropriate for spatial-variability characterisation. In 556 particular, Figure 4 has highlighted the need to holistically represent roughness using a range 557 of roughness parameters, such as those presented in this study, to gain an understanding of 558 the surface roughness and its spatial variability. This implication provides a step towards the

559 improvement to the calculation of flow resistance equations, which formerly used subjective 560 roughness coefficients, resulting in errors (Powell 2014). Contrasting with $\sigma_{z}$, we show that 561 grain imbrication and bed-elevation skewness vary greatly within a patch (Figure 4), which 562 has important implications when deciding which bed parameters to measure to explain 563 process heterogeneity, such as sediment transport.

\section{Suitable DEM size for grain-roughness characterisation}

565 We suggest that a DEM size exceeding $16 \times \mathrm{D}_{50 \mathrm{~A}}$ in both directions (which is the modal 566 plateau value from all roughness parameters and DEMs) is required to provide reliable grain567 roughness statistics. This recommendation of DEM size is supported by our previous work 568 (Bertin et al., 2017, Figures 2 and 6), whereby the analysis of roughness spatial variability was extended to 35 DEMs and included DEMs collected in a laboratory flume by Aberle and

570 Nikora (2006) and the Waimakariri River (Smart et al, 2004).

571 At first look, the plateaus obtained appear lower than the value of $21 \times \mathrm{D}_{50}$ deemed 572 appropriate for patch size in previous literature (Ockelford and Haynes, 2013). A possible 573 reason is that sediment size in our study is based on the armour (i.e., surface) layer, whilst we 574 believe Ockelford and Haynes (2013) refer to the subsurface (or bulk mixture) $\mathrm{D}_{50}$ (based on $575 \mathrm{D}_{50}$ of $4.8 \mathrm{~mm}$ ). To allow comparison, the thresholds obtained here need to be converted from 576 only considering the armour layer, to the subsurface layer too. Assuming an armouring ratio 577 of 2 (i.e. $\mathrm{D}_{50 \mathrm{~A}} / \mathrm{D}_{50}=2$ ), which has been measured for our experimental beds (cf. Table I) and 
578 observed in gravel-bed rivers in the field (Oldmeadow and Church, 2006), the thresholds in 579 this paper would be between $28-36 \times \mathrm{D}_{50}$. Therefore these thresholds are actually higher than 580 the $21 \times D_{50}$ suggested by Ockelford and Haynes (2013) and our results stress the importance

581 of sediment sorting and bedform prevalence (i.e., spatial organisation) on these thresholds.

582 Further, we believe this highlights the importance of a required uniformity within research for 583 data analysis procedures in order to facilitate comparisons between studies. This statement 584 supports a view in larger-scale studies, which, in order to delineate different features and 585 scales of roughness across a floodplain, have stated that research requires an automated 586 process to extract quantitative data from data of varying quality (Bertoldi et al. 2012).

587 Recommendations such as those presented here are a step towards achieving this.

588 Similar to this patch-scale work, Scown et al. (2016) found spatial organisation of a surface 589 and DEM size to influence measurements of floodplain topography and analytical 590 requirements. The fact that the same findings have been observed at two vastly different 591 spatial scales of fluvial surfaces (i.e., from $\mathrm{mm}$ to $\mathrm{km}$ ) is further evidence of a continuum of 592 roughness scales in the environment. Both studies also support the idea that analysis of 593 roughness spatial variability is effective in detecting transitions between scales, which is an 594 avenue of research that could benefit from further exploration.

\section{Suitable grid spacing for grain-roughness characterisation}

596 Our finding that grid spacing exceeding $1 \mathrm{~mm}$ is not able to identify grain imbrication has 597 implications for the collection of high-resolution topographic data. For the goal of grain598 roughness parameterisation, it is important to obtain a resolution which can adequately detect 599 individual grains, yet with the ability to be efficiently computated (e.g., use of a $1 \mathrm{~mm}$ grid 600 spacing rather than $0.2 \mathrm{~mm}$ in this study). Therefore the researcher should make a decision in 601 regards to computation time, and a compromise made between using a sufficient grid size 
602 (e.g., $1 \mathrm{~mm}$ ) and data quality desired. A major benefit of high resolution data is that the data 603 can be resampled at differing spacing required by the analysis (Ockelford and Haynes, 2013).

604 Future work could explore the effect of grid spacing on larger patches than those presented 605 here (as well as at floodplain scale, which was not formerly conducted), and determine 606 requirements for analysing bedform roughness.

\section{Conclusions}

608 In this study, we used an analytical process based on roughness spatial variability, aimed to 609 improve our understanding of how to analyse topographic data for gravel-bed roughness 610 parameterisation, which is of increasing relevance for fluvial research. We have found that

611 the scale of roughness under investigation is a vital pre-analysis decision required by the 612 researcher, as the surface morphology and structure can influence the analysis required for a 613 DEM. The study focused on grain-roughness characterisation using gravel-patch DEMs.

614 Firstly, spatial variability in microtopography across a gravel-bed was adequately quantified 615 using the moving-window analysis technique. This evident variability suggests that one 616 single roughness parameter, such as standard deviation, is not sufficient to represent grain617 scale roughness; therefore using a combination of roughness parameters, as presented in this 618 study, provides a more holistic view of surface complexity.

619 Secondly, the size of DEM influences the calculated roughness statistics, with a plateau in 620 variance observed between $16-18 \times \mathrm{D}_{50 \mathrm{~A}}$ in the field DEMs, and between $14-16 \times \mathrm{D}_{50 \mathrm{~A}}$ in the 621 laboratory, suggesting these DEM sizes provide robust measures of surface roughness. 622 Differences in the effect of DEM size between laboratory and field were found to be due to 623 multiple scales of roughness present on a gravel surface and differing sediment sorting.

624 Minimal differences between grid spacing below $1 \mathrm{~mm}$ indicate that the same quality results 625 can be obtained at less computation time, using the coarser grid spacing. However, it is 
626 essential for researchers to consider the scale of investigation, as using coarser resolutions

627 will cause a loss of topographic information and inadequately represent grain roughness,

628 rather focusing on roughness of larger scales, such as bedform roughness. This was

629 particularly apparent when quantifying grain imbrication, which failed for grid spacings

630 exceeding $1 \mathrm{~mm}$.

631 Based on this study, which considered patches of varying sediment size, surface morphology

632 and from different environments, we suggest for grain-scale roughness research using a DEM

633 size and therefore patch size exceeding $16 \times \mathrm{D}_{50 \mathrm{~A}}$ in both directions and using a grid spacing

634 of $1 \mathrm{~mm}$ or below. As these insights come from a range of environments and sediment, we

635 anticipate adequate roughness parameterisation in future research using guidance presented in 636 this paper, which will also facilitate comparisons between studies.

637 Acknowledgements:

638 The study was partly funded by the Marsden Fund (Grant No. UOA1412), administered by 639 the Royal Society of New Zealand. The authors would like to thank anonymous reviewers 640 whose constructive comments helped to improve the manuscript.

\section{References}

642 Aberle, J., and Nikora, V., 2006. Statistical Properties of Armored Gravel Bed Surfaces.

643 Water Resour. Res., 4211, W11414, DOI: 10.1029/WR004674

644 Aberle, J., and Smart, G., 2003. The Influence of Roughness Structure on Flow Resistance on 645 Steep Slopes. Journal of Hydraulic Research, 413, 259-269.

646 Baewert, H., Bimböse, M., Bryk, A., Rascher, E., Schmidt, K., Morche, D., 2014. Roughness

647 Determination of Coarse Grained Alpine River Bed Surfaces using Terrestrial Laser

648 Scanning Data. Zeitschrift Für Geomorphologie, Supplementary Issues, 581, 81-95. 
649 Barber, M. E., Grings, F. M., Álvarez-Mozos, J., Piscitelli, M., Perna, P. A., Karszenbaum, 650 H., 2016. Effects of Spatial Sampling Interval on Roughness Parameters and Microwave 651 Backscatter Over Agricultural Soil Surfaces. Remote Sensing, 86, 458.

652 Bergey, E. A., 2006. Measuring the Surface Roughness of Stream Stones. Hydrobiologia, $6535631,247-252$.

654 Bertin, S., and Friedrich, H., 2014. Measurement of Gravel-Bed Topography: Evaluation 655 Study Applying Statistical Roughness Analysis. J. Hydraul. Eng., 1403, 269-279.

656 Bertin, S., Friedrich, H., Delmas, P., Chan, E., and Gimel'farb, G., 2015. Digital stereo 657 photogrammetry for grain-scale monitoring of fluvial surfaces: Error evaluation and 658 workflow optimisation. ISPRS Journal of Photogrammetry and Remote Sensing, 101, 193659208.

660 Bertin, S., and Friedrich, H., 2016. Field Application of Close- range Digital 661 Photogrammetry CRDP for Grain- scale Fluvial Morphology Studies. Earth Surf. Process. 662 Landforms, DOI: 10.1002/esp.3906

663 Bertin, S., Groom, J. and Friedrich, H., 2017 Isolating roughness scales of gravel-bed 664 patches. Water Resour. Res., 53, 6841 - 6856. doi:10.1002/2016WR020205.

665 Bertoldi, W., Piegay, H., Buffin- Bélanger, T., Graham, D. and Rice, S. (2012) Applications 666 of Close- Range Imagery in River Research. Fluvial remote sensing for science and

668 Bouguet, J.-Y., 2010 Camera calibration toolbox for Matlab, Caltech, Pasadena, California. 669 Avaliable at: http://vision.caltech.edu/bouguetj/calib_docl

670 Buffin- Bélanger, T., Rice, S., Reid, I., Lancaster, J., 2006. Spatial Heterogeneity of 671 Near- bed Hydraulics Above a Patch of River Gravel. Water Resour. Res., 424. 
672 Casas, M., Lane, S., Hardy, R., Benito, G., Whiting, P., 2010. Reconstruction of

673 Subgrid- scale Topographic Variability and its Effect upon the Spatial Structure of

674 Three- dimensional River Flow. Water Resour. Res., 463.

675 Cienciala, P., and Hassan, M. A., 2016. Sampling Variability in Estimates of Flow

676 Characteristics in Coarse- bed Channels: Effects of Sample Size. Water Resour. Res., 52 ,

677 1899-1922, DOI: 10.1002/2015WR017259.

678 Coleman, S. E., Nikora, V. I., Aberle, J., 2011. Interpretation of Alluvial Beds through

679 Bed- elevation Distribution Moments. Water Resour. Res., 4711, W11505, DOI:

$680 \quad 10.1029 / 2011 \mathrm{WR} 010672$

681 Crowder, D. W., and Diplas, P., 1997. Sampling Heterogeneous Deposits in Gravel-Bed

682 Streams. J. Hydraul. Eng., 12312, 1106-1117.

683 Curran, J. C., and Waters, K. A., 2014. The Importance of Bed Sediment Sand Content for

684 the Structure of a Static Armor Layer in a Gravel Bed River. Journal of Geophysical

685 Research: Earth Surface, 1197, 1484-1497.

686 Detert, M., and Weitbrecht, V., 2012. Automatic Object Detection to Analyze the Geometry 687 of Gravel Grains-a Free Stand-Alone Tool. Proceedings of River Flow 2012, 595-600.

688 Erskine, R. H., Green, T. R., Ramirez, J. A., MacDonald, L. H., 2007. Digital Elevation 689 Accuracy and Grid Cell Size: Effects on Estimated Terrain Attributes. Soil Sci. Soc. Am. $690 \quad$ J., $714,1371-1380$.

691 Fehr, R., 1987. Geschiebeanalysen in Gebirgsflüssen: Umrechnung Und Vergleich Von 692 Verschiedenen Analyseverfahren, Versuchsanst. für Wasserbau, Hydrologie u. 693 Glaziologie.

694 Florinsky, I. V., and Kuryakova, G. A., 2000. Determination of Grid Size for Digital Terrain 695 Modelling in Landscape Investigations - exemplified by Soil Moisture Distribution at a 696 Micro-Scale. Int. J. Geogr. Inf. Sci., 148, 815-832. 
697 Fonstad, M., Dietrich, J., Courville, B., Jenson, J. and Carbonneau, P., 2013 Topographic

698 structure from motion: a new development in photogrammetric measurement. Earth Surf.

699 Process. and Landform, 384, 421-430.

700 Gao, J., 1998. Impact of Sampling Intervals on the Reliability of Topographic Variables

701 Mapped from Grid DEMs at a Micro-Scale. Int. J. Geogr. Inf. Sci., 128, 875-890.

702 Gimel'farb, G., 2002. Probabilistic Regularisation and Symmetry in Binocular Dynamic 703 Programming Stereo. Pattern Recog. Lett., 234, 431-442.

704 Graham, D. J., Rollet, A., Piégay, H., Rice, S. P., 2010. Maximizing the Accuracy of

705 Image- based Surface Sediment Sampling Techniques. Water Resour. Res., 462, W02508, 706 DOI: $10.1029 / 2008 W R 006840$

707 Grieve, S. W., Mudd, S. M., Milodowski, D. T., Clubb, F. J., Furbish, D. J., 2016. How does 708 Grid-Resolution Modulate the Topographic Expression of Geomorphic Processes? Earth 709 Surface Dynamics, 4, 627-653.

710 Haschenburger, J. K., and Wilcock, P. R., 2003. Partial Transport in a Natural Gravel Bed 711 Channel. Water Resour. Res., 391, DOI: 10.1029/2002WR001532

712 Heritage, G. L., Milan, D. J., Large, A. R., Fuller, I. C., 2009. Influence of Survey Strategy 713 and Interpolation Model on DEM Quality. Geomorphology, 1123, 334-344.

714 Hodge, R., Brasington, J., and Richards, K., 2009a. Analysing Laser- scanned Digital Terrain 715 Models of Gravel Bed Surfaces: Linking Morphology to Sediment Transport Processes 716 and Hydraulics. Sedimentology, 567, 2024-2043.

717 Hodge, R., Brasington, J., and Richards, K., 2009b. In Situ Characterization of Grain- scale 718 Fluvial Morphology using Terrestrial Laser Scanning. Earth Surf. Process. Landforms, $719347,954-968$. 
720 James, M. and Robson, S., 2012 Straightforward reconstruction of 3D surfaces and

721 topography with a camera: Accuracy and geoscience application. Journal of Geophysical

722 Research: Earth Surface 11F3.

723 Javernick, L., Brasington, J. and Caruso, B., 2014 Modelling the topography of shallow

724 braided rivers using Structure-from-Motion photogrammetry. Geomorphology, 213, 166-

$725 \quad 182$.

726 Jia, Z., and Hu, Z., 2015. Evaluation Methods of Material Surface Macro-Roughness.

727 Materials Research Innovations, 19, S8-293-S8-296.

728 Lane, S., James, T., Crowell, M., 2000. Application of Digital Photogrammetry to Complex

729 Topography for Geomorphological Research. The Photogrammetric Record, 1695, 793-

$730 \quad 821$

731 Lane, S. N., 2005. Roughness-time for a Re- evaluation? Earth Surf. Process. Landforms, $732 \quad 302,251-253$.

733 Laronne, J., and Carson, M., 1976. Interrelationships between Bed Morphology and

734 Bed- material Transport for a Small, Gravel- bed Channel. Sedimentology, 231, 67-85.

735 Mao, L., Cooper, J. R., Frostick, L. E., 2011. Grain Size and Topographical Differences

736 between Static and Mobile Armour Layers. Earth Surf. Process. Landforms, 3610, 1321-

$737 \quad 1334$

738 Martinez-Agirre, A., Álvarez-Mozos, J., Giménez, R., 2016. Evaluation of Surface

739 Roughness Parameters in Agricultural Soils with Different Tillage Conditions using a

$740 \quad$ Laser Profile Meter. Soil Tillage Res., 161, 19-30.

741 Milan, D. J., Heritage, G. L., Large, A. R., Fuller, I. C., 2011. Filtering Spatial Error from

742 DEMs: Implications for Morphological Change Estimation. Geomorphology, 1251, 160$743 \quad 171$. 
744 Milenković, M., Pfeifer, N., Glira, P., 2015. Applying Terrestrial Laser Scanning for Soil

745 Surface Roughness Assessment. Remote Sensing, 72, 2007-2045.

746 Millane, R., Weir, M., Smart, G., 2006. Automated Analysis of Imbrication and Flow

747 Direction in Alluvial Sediments using Laser-Scan Data. Journal of Sedimentary Research,

$748 \quad 768,1049-1055$.

749 Morvan, H., Knight, D., Wright, N., Tang, X., Crossley, A., 2008. The Concept of Roughness

750 in Fluvial Hydraulics and its Formulation in 1D, 2D and 3D Numerical Simulation

751 Models. Journal of Hydraulic Research, 462, 191-208.

752 Nelson, P., Bellugi, D. and Dietrich, W., 2014 Delineation of river bed-surface patches by 753 clustering high-resolution spatial grain size data. Geomorphology, 205, 102-119. DOI:

$754 \quad 10.1016 /$ j.geomorph.2012.06.008

755 Nikora, V. I., Goring, D. G., Biggs, B. J., 1998. On Gravel- bed Roughness Characterization. $756 \quad$ Water Resour. Res., 343, 517-527.

757 Noss, C., and Lorke, A., 2016. Roughness, Resistance, and Dispersion: Relationships in 758 Small Streams. Water Resour. Res., 524, 2802-2821.

759 Ockelford, A., and Haynes, H., 2013. The Impact of Stress History on Bed Structure. Earth $760 \quad$ Surf. Process. Landforms, 387, 717-727.

761 Oldmeadow, D. F., and Church, M., 2006. A Field Experiment on Streambed Stabilization by 762 Gravel Structures. Geomorphology, 783, 335-350.

763 Pearson, E., Smith, M., Klaar, M. and Brown, L., 2017. Can high resolution 3D topographic 764 surveys provide reliable grian size estimates in gravel bed rivers? Geomorphology, 293, $765 \quad 143-155$.

766 Piedra, M. M., Haynes, H., Hoey, T. B., 2012. The Spatial Distribution of Coarse Surface 767 Grains and the Stability of Gravel River Beds. Sedimentology, 593, 1014-1029. 
768 Powell, D.M. (2014) Flow resistance in gravel-bed rivers: Progress in research. Earth-Science Reviews 136, 301-338.

770

771 Powell, D. M., Ockelford, A., Rice, S. P., Hillier, J. K., Nguyen, T., Reid, I., Tate, N. \& 772 Ackerley, D., 2016. Structural properties of mobile armors formed at different flow 773 strengths in gravel- bed rivers. Journal of Geophysical Research: Earth Surface, 1218, 774 1494-1515.

775 Qin, J., and Ng, S., 2012. Estimation of Effective Roughness for Water-Worked Gravel 776 Surfaces. J. Hydraul. Eng., 13811, 923-934.

777 Rice, S. P., Buffin- Bélanger, T., Reid, I., 2014. Sensitivity of Interfacial Hydraulics to the 778 Microtopographic Roughness of Water- lain Gravels. Earth Surf. Process. Landforms, $779 \quad 392,184-199$.

780 Robson, B., Chester, E., Barmuta, L., 2002. Using Fractal Geometry to make Rapid Field 781 Measurements of Riverbed Topography at Ecologically Useful Spatial Scales. Marine and $782 \quad$ Freshwater Research, 536, 999-1003.

783 Scown, M. W., Thoms, M. C., De Jager, N. R., 2015. Measuring Floodplain Spatial Patterns 784 using Continuous Surface Metrics at Multiple Scales. Geomorphology, 245, 87-101.

785 Scown, M. W., Thoms, M.C. and De Jager, N. R., 2016 An index of floodplain surface 786 complexity. Hydrology and Earth System Sciences, 201, 431-441.

787 Smart, G., Aberle, J., Duncan, M., Walsh, J., 2004. Measurement and Analysis of Alluvial 788 Bed Roughness. Journal of Hydraulic Research, 423, 227-237.

789 Smart, G. M., Duncan, M. J., Walsh, J. M., 2002. Relatively Rough Flow Resistance 790 Equations. J. Hydraul. Eng., 1286, 568-578.

791 Smith, M., Vericat, D., Gibbins, C., 2012. Through-Water Terrestrial Laser Scanning of 792 Gravel Beds at the Patch Scale. Earth Surf. Process. Landforms, 374, 411-421. 
793 Smith, M. W. 2014. Roughness in the Earth Sciences. Earth-Sci. Rev., 136, 202-225.

794 Stähly, S., Friedrich, H., \& Detert, M., 2017. Size Ratio of Fluvial Grains’ Intermediate Axes 795 Assessed by Image Processing and Square-Hole Sieving. Journal of Hydraulic 796 Engineering, 06017005.

797 Trevisani, S., and Cavalli, M., 2016. Topography-Based Flow-Directional Roughness:

798 Potential and Challenges. Earth Surface Dynamics, 4, 343-358.

799 Tuijnder, A. P., and Ribberink, J. S., 2012. Experimental Observation and Modelling of 800 Roughness Variation due to Supply-Limited Sediment Transport in Uni-Directional Flow. $801 \quad$ Journal of Hydraulic Research, 505, 506-520.

802 Wackrow, R. and Chandler, J., 2008 A convergent image configuration for DEM extraction 803 that minimises the systematic effects caused by an inaccurate lens model. The 804 Photogrammetric Record, 23121, 6-18.

805 Wilcock, P., 1996. Estimating local bed shear stress from velocity observations. Water $806 \quad$ Resour. Res. 3211, 3361 - 3366.

807 Zhang, W., and Montgomery, D. R., 1994. Digital Elevation Model Grid Size, Landscape 808 Representation, and Hydrologic Simulations. Water Resour. Res., 304, 1019-1028.

809 Zhang, Z., 2000. A Flexible New Technique for Camera Calibration. IEEE Trans. Pattern $810 \quad$ Anal. Mach. Intell., 2211, 1330-1334.

811 